\section{POST-SALVARSAN JAUNDICE}

BY A. T. TODD, O.B.E., M.B. EdIN., M.R.C.P. Lond., MAJOR, R.A.M.C, ; CONSULTANT PHYSICIAN, RHINE FORCES.

DATING from October, 1920, a small epidemic of jaundice following treatment of syphilis by novarsenobillon has been noted in the Rhine army. The first case of the series died five days after admission to hospital, and was diagnosed acute yellow atrophy at the autopsy. Several more cases, clinically similar, were admitted shortly after this occurrence, and I was led to examine for evidence of hepatic disturbance and acidosis. The findings were so constant, had so much bearing upon prognosis and treatment, and were so different from the findings in jaundice from other causes that I think they may be of interest.

The series comprises 24 cases of " 914 " jaundice, and as controls 15 cases of jaundice in patients who were non-syphilitic and had not had any arsenical treatment. I do not propose to discuss the exciting cause of the jaundice, for that has been considered already by several observers, who conclude that it is the arsenical radicle of novarsenobillon. In the literature at my disposal there is only one dissentient on this point, E. G. Ffrench, who concludes that the jaundice is due to syphilis itself in some cases, and that it occurs with some frequency in patients who have received no " 914 " or other arsenical preparation. However, H. D. Rolleston ${ }^{2}$ states that jaundice in secondary syphilis is rare, and quotes figures of Werner and Goldstein showing that jaundice occurs only 77 times in 23,261 cases of syphilis before the introduction of salvarsan. Nicaud, ${ }^{3}$ G. E. Strathy, C. H. V. Smith and B. Hannah, ${ }^{4}$ and R. Hallam, conclude that the jaundice is due to arsenic. Moreover, the jaundice of secondary syphilis is said to be hæmolytic in type ${ }^{6}$; Nicaud ${ }^{7}$ determined the fragility of the red blood corpuscles in a series of his cases, and found an increase of resistance; in two cases of the present series I tested the fragility and found definite increase. The treatment of jaundice due to syphilis is that of syphilis (Rolleston); in " 914 " cases further exhibition of arsenical preparations aggravates the condition. Moreover, if the condition were due to active syphilis a positive Wassermann reaction should be present; this was not found to be the case in the present series. It has not yet been proved whether the toxicity is due to arsenic properly combined as novarsenobillon, or whether it is due to some arsenical impurity ; Hallam ${ }^{8}$ could find no impurity in the samples supplied to him in his series.

No case of this jaundice appeared during the period March-September, 1920. The occurrence of the epidemic coincided with the onset of cold weather. The explanation of this is probably twofold: (a) the seasonal incidence of afebrile jaundice has been shown to reach its maximum in the winter months, ${ }^{9}$ and $(b)$ a heavier burden is thrown upon an embarrassed liver by the winter diet rich in fats and proteins. The time of onset of symptoms relative to the dosage of " 914 " received shows no difference from what has previously been observed. The smallest total dosage of " 914 " in this series was $4^{\circ} 05 \mathrm{~g}$., the largest, $12.15 \mathrm{~g}$. The time of onset after the last injection varies from one day to 17 weeks, the average being 10 weeks. Nicaud ${ }^{10}$ divides "914" jaundice into early and late types-that is, occurring soon after small or late after large dosages. He came to the conclusion that the early cases had a more serious prognosis. In this series such a division could not be made; some of the late cases were mild, some severe, and vice versa.

The investigations made include clinical findings and narration of symptoms, as these differ from those found in catarrhal jaundice, and are therefore of importance in differential diagnosis. The urinary investigations comprise examination of the amount, acidity, presence of albumin, casts, sugar, acetone, deposit of leucin and tyrosin, bile pigments and acids, urobilin, percentage of urea, estimation of ammonia, and the ammonia-urea nitrogen ratio. The diastase was estimated in each case from time to time. These examinations were made daily until convalescence was established. All the quantitative and most of the qualitative examinations were made by myself with the same apparatus throughout.

IIorbid Anatomy.

In brief, the morbid anatomy appears to be a hepatitis leading to fatty degeneration (v.Nicaud's early autopsy ${ }^{11}$ ), followed by cell death and compensatory fibrosis of periportal distribution. The fibrosis would appear to be responsible for the further atrophy and shrinkage of the liver. Next in severity to the liver the kidneys are concerned, and show a marked degeneration and atrophy of the tubular epithelium. Fatty degeneration of most tissues is present. Hæmorrhages into brain, Iungs, pleura, pericardium, and peritoneum are common in fatal cases. The liver shrinkage in life was demon strated in 30 cases by $\mathrm{X}$ ray measurement. ${ }^{12}$ In addition, Strauss ${ }^{13}$ describes ascites in one fatal case.

In an early case it would be expected that a normal. sized, or rather enlarged, liver would be encountered, the enlargement being due to one or more of the following conditions: vascular engorgement, fatty degeneration, or small-celled infiltration; acidosis should be present from defective protein metabolism. As the condition progresses to convalescence or death shrinkage would result from diminution of the hepatitis or further atrophy. It will be seen in the next section that these conceptions are justified.

\section{symptoms.}

The presenting symptoms as compared with those of catarrhal jaundice appear in Table $\mathrm{I}$. TABLE I.

\begin{tabular}{|c|c|c|c|c|c|c|c|c|c|c|c|c|}
\hline ype. & $\begin{array}{l}\vec{c} \\
\dot{c} \\
\dot{z} \\
z\end{array}$ & 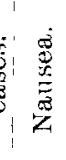 & 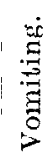 & $1 . \frac{8}{0}$ & 葛 & 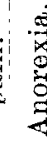 & & & & 童 & 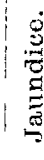 & \\
\hline & & 33 & $\begin{array}{l}90 \\
10 \\
22\end{array}$ & $\begin{array}{l}\% \\
41\end{array}$ & $\begin{array}{l}\% \\
58\end{array}$ & $\begin{array}{l}\% \\
45\end{array}$ & & & 15 & $\begin{array}{l}a_{0} \\
0\end{array}$ & $\begin{array}{l}\% \\
55\end{array}$ & \\
\hline atarrhal jaundic & & 67 & 53 & 33 & 44 & 53 & & & 16 & 0 & 48 & \\
\hline
\end{tabular}

The character of the symptoms in the two classes show no marked differences, with the exception of abdominal pain, which in the " 914 " group showed no relationship to food; in three cases, all showing definite evidence of liver enlargement, the pain was dependent upon posture, being aggravated by lying upon the left side. The abdominal, just as the cephalic pain was not well localised. Shoulder pain was not observed. Dimness of vision occurred in the fatal case three days before death.

Clinical Findings.

The clinical findings in the two groups appear in Table II.

TABLE II.

\begin{tabular}{|c|c|c|c|c|c|c|c|c|c|c|c|}
\hline Type. & & 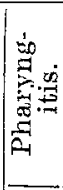 & 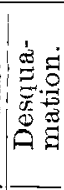 & 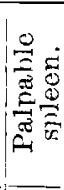 & 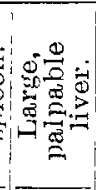 & 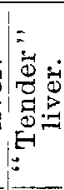 & 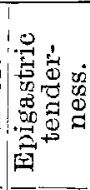 & 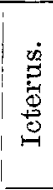 & 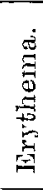 & 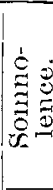 & 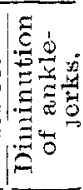 \\
\hline "914" ... & & $\begin{array}{c}\% \\
9\end{array}$ & $\begin{array}{l}\% \\
30\end{array}$ & $\begin{array}{r}\% \\
5\end{array}$ & $\begin{array}{l}\% \\
38\end{array}$ & $\begin{array}{l}\% \\
33\end{array}$ & $\begin{array}{l}\% \\
50\end{array}$ & $\begin{array}{c}\% \\
100\end{array}$ & $\begin{array}{c}\% \\
9\end{array}$ & $\begin{array}{l}\% \\
22 \\
22\end{array}$ & $\begin{array}{l}0 \\
9 \\
9 \\
9\end{array}$ \\
\hline Catarrhal ... & $\ldots$ & 0 & 7 & 13 & 7 & 13 & 27 & 100 & 0 & 0 & 0 \\
\hline
\end{tabular}

Pyrexia was not observed; the one fatal case showed a subnormal temperature. The skin desquamation affected chiefly the extensor surfaces of the limbs; in a few cases the trunk, especially the chest, showed scaling; there was no associated dermatitis.

Condition of liver.-In the " 914 " group the liver was definitely palpable and enlarged in 38 per cent. of the cases; the real percentage is certainly higher, for the pain evoked by palpation was so severe, or caused so much boarding of the abdominal muscles, that the attempt was given up. In all these cases the superior liver dullness was normal and the consistence of the liver was distinctly hard, in some cases giving the 
impression of wood; in about one-third of the cases there was pain or discomfort, as the sharp lower edge slipped over the palpating thumb (procédé de pouce). In one case there was definite evidence of a small-sized liver; in this case fatty casts were found in the urine. In an important percentage of the " 914 " group the liver was enlarged and altered in consistence.

The erythema noted was similar to that observed by Sicard. ${ }^{14}$ Absence of Achilles jerk is regarded by Sicard as an important early sign or arsenical neuritis; diminution on one side was noted, no complete absence of ankle-jerks occurred. The eye-grounds of several severe cases were examined by the ophthalmological specialist, Captain Pringle, R.A.M.C., who found nothing abnormal. The liver condition changes with the progress of the case ; in three cases only did the enlargement persist in convalescence, and these cases were three of the most severe. When enlargement persists it may be assumed that the cirrhotic changes are permanent.

Somnolence was noted only when distinctly more marked than the depression and lethargy common in other forms of jaundice. The one fatal case developed somnolence after two days in hospital ; it was accompanied by delirium and rapidly deepened to coma. The same somnolence was noted in the earlier cases of the series by the M.O. in charge of the medical wards, who directed my attention to them as possible cases of acute yellow atrophy. Instructions were then sent out to all M.O.'s of units to watch for cases of jaundice in men who had had treatment for syphilis, and to send cases to hospital when discovered. The result was that, with one or two exceptions, the later cases were much milder, and somnolence was not noted again. This somnolence, I suspected, was due to disturbed hepatic metabolism; I accordingly examined for a resulting acidosis. Strathy ${ }^{15}$ suspected acidosis, but gives no figures. The estimation of acidosis was accomplished by comparing the ratio of the ammonia nitrogen to that of the urea. According to Panton, ${ }^{16}$ "A reliable guide to the extent of the acidosis can be obtained from a comparison of the ammonia and urea nitrogen.' Samples of normal urine, of urine of diabetes, of catarrhal jaundice, and of patients who had had much

" 914 " treatment were examined, and the results of the catarrhal cases are included and are referred to as "jaundice controls."

\section{Urinary Findings.}

It is regretted that no urinary examination was made in the fatal case; this case occurred in my absence. To detail the findings in each case would require too much space; amongst other examinations the ammoniaurea nitrogen ratio was determined 500 times. Many of the results may be summarised and dismissed briefly. The urine of each patient was collected in a receptacle stored in a cool place; all examinations were made with complete 24 hours' specimens.

Amount.-Usually diminished, the average being $45 \frac{1}{3}$ fluid ounces during the first complete 24 hours. The diminution appeared to be proportionate to the severity of the case. On the fifth day the urine averaged 59 fluid ounces. Jaundice controls (catarrhal or apyrectic jaundice) showed like amounts, 45 ounces on admission, increasing to 66 ounces on the fifth day.

Acidity.-High on admission, requiring $34.5 \mathrm{c.cm}$. decinormal caustic soda per cent. for neutralisation. This diminished rapidly, and on the fifth day averaged $15.5 \mathrm{c.cm}$ Controls averaged $22 \mathrm{c.cm}$. per cent. on admission, and $14 \cdot 1 \mathrm{c.cm}$. on the fifth day.

Albumin.-Present in 14 per cent. of the cases. It disappeared in convalescence, was slight in amount, never more than a trace being noted. The jaundice controls showed no albumin.

Bile pigment.-Gmelin's test was positive in.92 per cent. of the cases on admission.

Urobilin.-Present in the 8 per cent. of the cases in which bile pigment was absent. Schlesinger's test and the test of Morel and Policard ${ }^{17}$ were applied in each case. Orobilin was generally found present several days after bile pigment had disappeared. Urobilin, unaccompanied by bile pigment, was not found in the catarrhal control, though its occurrence has been noted.18

Bile acids.-Hay's test was performed in every case until the severe and mild cases alike failed to give a positive reaction.
Deposit.-Detailed notes were not kept in all cases. Sediment asually consisted of amorphous urates; uric acid crystals were occasionally, and oxalate crystals were frequently, noted. Pus corpuscles were commonly present, and on three occasions showed well-marked, deeply stained globules with osmic acid. No blood was noted. Oxalate crystals were also found in many of the jaundice controls.

Casts.-Present in 11 per cent.; usually granular or hyaline. Fatty casts were sought in each case, but were found in one only.

Leucin and tyrosin.--Sought in the deposit of each case but never found. Precipitation methods were not employed. Suyar.-No case showed presence of reducing substances. Acetone.-Not found.

Urea.-The percentage on admission was high, the average being 2.4 per cent. Jaundice controls averaged 1.68 per cent. In both classes the urea percentage rapidly diminished owing to the special diet given.

Ammonia-urea nitrogen ratio.-The formalin method, as described by Panton, was employed for the ammonia estimation; for the urea the hydrobromite method. For the former $20 \mathrm{c.cm}$. of urine were taken, and for the latter $4 \mathrm{c.cm}$. The calculation of the contained nitrogen is simplified by multiplying the number of cubic centimetres of decinormal sodium hydroxide solution used, after adding the neutral formalin, by 14 ; the number of cubic centimetres of nitrogen evolved is multiplied by $58 \cdot 33$, the latter constant being worked out on the basis that $16 \mathrm{c.cm}$. nitrogen correspond to 1 per cent. urea. ${ }^{19}$ This figure is rather high; $15 \mathrm{c.cm}$. are given by Plimmer. 20 The division of the former figure in to the latter gives the ratio-ammonia nit.: urea nit. :: $1: x$. For brevity the latter figure only is given. On the day of admission the ratio averages $9 \cdot 35$, the lowest being 6.0 and the highest $15 \cdot 0$. "Under normal conditions the ammonia nitrogen is about one-twentieth of the urea nitrogen, and in conditions associated with acidosis it may rise to one-fourth. $A$ rise in the ammonia nitrogen to one-tenth of the area nitrogen is definite evidence of acidosis." 21 Seventy. one per cent. of the cases show a ratio of less than 10 -i.e., one-tenth-on the day of admission. Taking the average of the clinically severe cases, the ratio was found to be $8 \cdot 1$; the average of the cases showing somnolence is 8.0 . The average ratio after four days in hospital was found to be $22 \cdot 0$-i.e., one twenty-second. Some of the cases did not show an acidosis on the day of admission, but the ratio of ammonia nit.: urea nit., in some cases dropped below the acidosis level on the second, third, or fourth day. At some time during the acute stage of the illness acidosis was determined in 80 per cent. of the cases, and was present in all but the slight cases.

In the jaundice controls the average ratio on admission was 16.3 . After five days it averaged $22 \cdot 0$. In only one case did the figure fall below 10.0 , and this was regarded as being due to ammoniacal fermentation, for the acidity was very low, and triple phosphates were found in the deposit. It should be noted here that all the cases, controls also, were treated in the same ward, had the same diet, and the same medicinal treatment, with the exception that in one or two of the catarrhal group pill fel bovini was given t.d.s.

I am aware that catarrhal jaundice, in some schools at least, is no longer regarded as merely a symptomcomplex brought about by the damming up of bile by an acute stenosis of the bile-ducts due to catarrhal cholangitis, but as a lesion of the hepatic cells, which interferes with the hepatic function as a whole. ${ }^{22}$ But the figures given above appear to show that the hepatic function is much more severely embarrassed in the "914" cases.

Urinary diastase.-This was measured partly to determine whether there was evidence of pancreatic involvement, and partly because it was considered possible that differential diagnosis in catarrhal cases might be facilitated; for a pancreatic origin in certain cases of catarrhal jaundice is considered by Rolleston. An associated catarrh of the duct of Wirsung might accompany that of the common bile-duct. The Wohlgemuth technique as described by Wallis ${ }^{23}$ was followed; in all 140 estimations were made. Figures on the whole show an increased amount of diastase; in 42 per cent. of the cases the figure reached or exceeded 40 ; the highest figure noted was 100 units, which fell to 20 units within seven days. Figures of 50-60 units were fairly common. In 19 per cent. of the cases the figure dropped below 10 units at some time; the lowest figure reached was 6 units, but this is regarded as the lowest normal limit by Maclean and Russell.24 The remaining 39 per cent. gave normal diastase figures throughout the illness-i.e., 10-30 units. This increase is of interest, as it may demonstrate pancreatic involvement or may be regarded as further evidence of hepatic embarrassment ; for an increase of the diastase has been found constantly in the toxæmias of pregnancy, 25 in 
which condition hepatic involvement is generally conceded. In all cases where the diastase showed normal values the figure became normal in a few days. This examination was found to be of little value in differential diagnosis, for a similar increase, varying between 40 and 80 units, was found in 28 per cent. of the jaundice controls; this is further evidence for the presence of pancreatic changes in catarrhal jaundice.

The urinary findings justify the opinion that a lesion of the liver tissue is present and that an acidosis results; for 80 per cent. of the cases showed evidence of acidosis at some period of the illness. Moreover, the degree of acidosis was proportional to the severity of the clinical findings; also the acidosis disappeared as the other symptoms subsided.

\section{Course of the Illness.}

The average of the cases shows that the period spent under close observation was 22 days; about three days added to this gives the average time spent in hospital. The last day after admission on .which acidosis was present averaged the fourth day. No case was discharged from hospital until he had been on the full diet for a week, and had performed some light duty. So far no relapses have occurred.

\section{Proqnosis.}

The case mortality is diffcult to determine. From the literature quoted I have been able to obtain figures in 141 cases; amongst these 23 deaths are recorded, giving a mortality of 16.3 per cent. This figure may be too high, for, possibly, some early deaths, not due to hepatitis, are included. On the other hand, it is highly probable that some of the fatalities have been described as acute yellow atrophy, for this condition, formerly a great rarity, appears to be fairly common at present, und comparatively numerous cases are described in the current European literature. The present series, which is not included in the above figure, shows a mortality of $4 \cdot 1$ per cent.--i.e., one case, the first of the series, who did not receive any specific treatment. Series of cases show very variable mortality rates; both in Hallam's and Nicaud's series no deaths are recorded.

\section{Treatment.}

All the cases were kept in bed until chicken diet was ordered. Fluids were given freely, especially imperial drink. The only routine drug treatment given was sod. bicarb. 60 grains t.d.s. Laxatives were ordered when required. For 24 hours after admission fall diet and no treatment was given in order that the gravity of the case could be determined. After this the patient was put on the following diets, one after another, as the urinary and clinical findings improved : (1) starch diet: in this proteins and fat are excladed, the diet consisting of bread, fruit, boiled vegetables, milk puddings (made with very little milk), jelly (as a protein sparer), and tea without milk; (2) fish diet: the addition of boiled fish being made to the starch diet; (3) fish and eggs: one or two eggs per diem in addition to the fish (4) chicken diet: the ordinary chicken diet of the hospitals, the patient being allowed out of bed; (5) ordinary diet: when this was given the patient was encouraged to help in the ward. It may here be noted that the recovery of the jaundice controls appeared to be accelerated by this treatment.

My thanks are due to the D.D.M.S., Rhine Forces, for issuing instructions to all M.O.'s of unit and otherwise facilitating the investigations; also to Major $\mathrm{E}$. F. Bashford, O.B.E., R.A.M.C. (T.C.), D.A.D. Pathology, for permission to perform examinations in the laboratory.

References.-1. Ffrench, E. G.: The Lancet, 1920, i., p. 1262. 2. Rolleston: Dis. Liver, p. 449. 3. Nicaud: Presse Méd., May 22nd, 1920. 4. Strathy, G. E., Smith, C. H. V., and Hannah, B. THE LANCET, $1920, \dot{i} .$, p. 802. 5. Hallam, R.: THE LANCET, 1920, $i$, p. 1356. 6. Rolleston : Dis. Liver, p. 350. 7. Nieaud: Loc cit. 8. Hallam, R.: Loc. cit. 9: Garnier and Reilley: Presse Méd.
Nov. 13th, 1920. 10. Nicaud : Loc. eit. 11. Loc. cit. 12. Strathy Nov. 13th, 1920. 10. Nicaud : Loc. eit. 11, Loc. cit. 12. Strathy Loc. cit. 13. Strauss : Berl. Klin. Woch. June, 1920. 14. Sicard Presse Méd., May, 1920. 15. Loc. eit. 16. Clinical Pathology, p. 230.
17. Martinet: Diag. clinique, 1920 . 18 . Rolleston: Dis. Liver. 17. Martinet: Diag. Clinique, 1920. 18. Rolleston: Dis. Liver. 19. Maclean, H., and Russell, A. E.: THe LANCET, 1920, i., p. 1305. 22. Oddo: Thèse de Paris, 1920. 23. Mackenzie Wallis: Brit. Med Jour., 1920, ii., p. 273. 24. Maclean and Russell: Loc. cit. 25. Mackenzie Wailis, Loc. cit.

\section{GENERALIA ON THE \\ LOUSE PROBLEM AT THE WESTERN FRONT.}

BY A. D. PEACOCK, M.Sc.,

ARMSTRONG COLLEGE, UNIVERSTTY OF DURHAM.

IN order to round off my records of the results of about three and a half years' continuous work, mostly in Flanders, on various aspects of the louse problem. I publish the following few remaining generalia from my notebooks. They are somewhat belated, but many post-war duties have prevented their collation.

Viability of Lice.

Through the kindness of Mr. A. W. Bacot, of the Lister Institute of Preventive Medicine, a supply of nits and about 300 lice of all ages were forwarded to me in France for certain experiments. The eggs were attached to small pieces of khaki cloth upon which the insects were at liberty to cling and crawl. All were dispatched in a round wooden pill-box $1 \frac{1}{2}$ inches in diameter and of the same depth. The insects had been given opportunity to feed at about 4 P.M. on Oct. 22 nd, 1918, and were then packed and placed in the post They reached the laboratory in France on Oct. 29 th and, with the exception of a few which were set aside for viability experiments, were allowed to feed at 2 P.M. The survivors which fed numbered 138-approximately one-half of the original number dispatched-were of all ages except, of course, newly hatched specimens. Thus a fast of 6 days 22 hours apart from the human host, at an unknown temperature in the post, was well within the powers of the insects. Similar observations to this have been recorded by many observers, but the two following experiments present new features.

\section{Experiment 1.}

Oct. 22nd, 1918, 4 P.M.: Lice given opportunity to feed by Mr. Ba.cot.

Oct. 29th, 11.30 A.M.: 2 nymphs and 1 larva in second instar separated and placed in incubator at $28^{\circ} \mathrm{C}$

Oct. 31st, 10 A.M. : All fed after a little elfort, one standing on its head to do so. 2.30 P.M. and 6.30 P.M.: All fed; kept in an incubator at $28^{\circ} \mathrm{C}$. between feeds.

Nov. 1st, 9.15 A.M.: Only 1 nymph fed; the second nymph still alive, but too feeble to feed though given 30 minutes to do so: killed. Larva dead. 6.30 P.M. : Survivor fed.

Nov. 2 nd, 10 A.M., 3 P.M., and 6.45 P.M.: Survivor fed.

Nov. 3rd, 9.15 A.M. and 6.30 P.M. : Survivor fed.

Nov. 4th, 11.15 A.M. : Survivor did not feed; incubator had failed, and louse exposed to room temperature for several hours. (Temperature not noted.) 6.30 P.At.: Appears nearly dead-ruptured.

\section{Experiment}

Oct. 22nd, 1918, 4 P.M. : Lice given opportunity to feed.

Oct. 29 th, 11.30 A.M.: 3 nymuphs and 2 larvæe in the second instar separated and placed in incubator at $28^{\circ} \mathrm{C}$.

Oct. 3lst, 10 A.M.: Lice removed and kept on bench at abou $15^{\circ} \mathrm{C}$.; still able to crawl feebly. 5.15 P.M. : Given opportunity to feed; the 3 nymphs settled and fed almost immediately; on larva was more tardy in feeding, while the other crawled around feebly before settling, and did not feed till some time after; the larvæ were the feeblest of all. Subsequently, between feeds, kilt in incubator at $28^{\circ} \mathrm{C}$.

Nov. 1st, 9.15 A.Mr.: 4 fed; one larva failed to feed after 30 minutes and subsequently died. 6.30 P.M.: 4 fed.

Nov. 2nd, 10 A.M.: 3 nymphs fed. The larva fell into a borl which had been wiped with strong cresol and never fed afterwards. 3 P.M. and 6.45 P.M. : 3 survivors fed.

Nov, 3rd and 5th: All fed twice a day, morning and evening. Nov.6th: All appear perfectly healthy; added to stock.

These experiments and observations show: (1) that nymphs and larvæ in the second instar may survive a fast and separation from the human host of 9 days

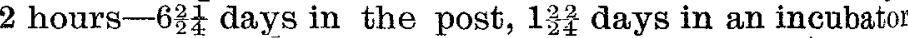
at $28^{\circ} \mathrm{C}$., and $0 \frac{7}{4}^{-}$day in a laboratory at $15^{\circ} \mathrm{C}$.; (2) that, moreover, though very enfeebled after their fast, they still had strength enough to feed and subsequently recover; (3) that this period of fasting and separation from the human host approximates very closely to the limits of endurance of the insects.

These conclusions are of interest because, to my know. ledge, no other records show for similar conditions quite such a high viability for the louse. It is of interest, too, that these hardy specimens were nymphs, and presumably about the prime of life.

$$
\text { A Clothing Repair Depôt. }
$$

Compared with that of the bug or flea the viability of the louse is very low; this fortunate fact is well illustrated as follows. 